\title{
Determination of Tamarindus Indica Seed Fatty Acid Components Using Ultrasound- Assisted Microwave Extraction Method
}

\author{
Özlen Özkurt ${ }^{1, b}$, Rıfat Battaloğlu ${ }^{1, a, *}$ \\ ${ }^{I}$ Department of Chemistry, Science and Art Faculty, Niğde Ömer Halisdemir University, 51245 Campus, Niğde, Turkey \\ *Corresponding author

A R T I CLE IN F O A B S T R A C T \\ Research Article \\ In this study aimed to determine the effect of ultrasound and microwave assisted extraction on \\ fatty acids yield. Fatty acid components of Tamarindus Indica ( $T$. Indica) seed were determined \\ using ultrasound assisted microwave extraction method. T. Indica is cultivated in the tropics and \\ in Egypt and India. Its fruits are 12-15 cm long, brown and leguminous. In addition to its positive \\ effects on the digestive system, it is an excellent source of vitamin $\mathrm{C}$ and a rich antioxidant. It has \\ Received : 24/10/2021 \\ Accepted : 17/11/2021 \\ also been proven beneficial in keeping blood sugar balanced. Fatty acid components were \\ determined by Gas Chromatography-Mass Spectroscopy (GC-MS) method. In addition, the \\ effects of the solvent on the fatty acid yield were investigated. When the results of the analysis \\ were examined, the highest yield was obtained when ethyl alcohol and methyl alcohol were used \\ as solvents. Another important solvent is acetone. The least product was achieved when hexane \\ Keywords: \\ Tamarindus Indica \\ Fatty acid \\ Microwave extraction \\ Soxhlet Extraction \\ was used as solvent. Linoleic acid and arachidic acid were detected in each type of solvent used. \\ Capric acid, ligroseric acid and nervotic acid, which are important fatty acids, are detected only \\ in methyl alcohol extraction. The ultrasound assisted microwave extraction method was found to \\ be much faster than the traditional Soxhlet extraction method.
}

Effect of solvent

\section{Introduction}

T. Indica is a tropical evergreen tree native to fertile areas throughout Southern Asia and Africa. It is widely cultivated as an ornamental tree and for its acidic fruits used in making drinks and a popular component of many decoctions used as health remedies. In Northern Nigeria, the fresh stem bark and fresh leaves are used as decoction mixed with potash for the treatment of stomach disorder, general body pain, jaundice, yellow fever and as blood tonic and skin cleanser. Because of its wide usage and availability, this study was set out to investigate the antimicrobial activity of the plant and to determine the effect of temperature and $\mathrm{pH}$ on the efficacy of the plant as an antimicrobial agent. Tamarindus is a monotypic genus and belongs to the subfamily Caesalpinioideae of the family Leguminosae (Fabaceae), Tamarindus indica L., commonly known as Tamarind tree is one of the most important multipurpose tropical fruit tree species in the Indian subcontinent (De Caluwé et. All 2010; Bhadoriya et. all, 2012).
Fats are glycerine triesters of even carbon number (424) saturated and unsaturated fatty acids. It consists of hydrogen $(\mathrm{H})$, carbon $(\mathrm{C})$ and oxygen $(\mathrm{O})$. Fatty acids are long, straight-chain, double-carbon monocarboxylic acids. They are also called glycerides because glycerin is used in oil formation. Insoluble in water; Some of the lipids in chemical structure that dissolve in solvents such as ether, gasoline, acetone, form oils. Fats are important when dieting, and they are a mandatory nutrient to be taken with protein and carbohydrates (Taşan and Geçgel, 2007). It is of great importance in terms of health as well as its necessity for nutrition). Compounds with different structures that are insoluble in water but soluble in organic solvents such as ether, benzene, chloroform are defined as oil (Karaca and Aytaç, 2007). Based on their sources, lipids are classified as vegetable oils, animal fats, mineral, essential oils and waxes. Lipid types are divided into three as simple lipids, compound lipids and sterols. Simple lipids are oils and waxes. Compound lipids are phospholipids, 
glycolipids, and lipolipids. Fats are formed by the combination of fatty acids and glycerol molecules. The excess of carbon and hydrogen in the composition of fats makes them a richer source of energy compared to carbohydrates. Fatty acids form the hydrophobic family of biomolecules. Only a small part of the total oil obtained from extraction with non-polar solvents consists of long chain carboxylic acids. Most of the carboxylic acids of biological origin exist in the form of esters of glycerol (glycerine) and these are called triacylglycerols. Triacylglycerols are oils of vegetable or animal origin. Oils to triacylglycerols, which are liquid at room temperature; Solids are also called solid fats. Triacylglycerols with the same three acyl groups are simple triacylglycerols. Triacylglycerols with different acyl groups are called mixed triacylglycerols and are the most common (Donnis et al., 2009).

Microwave assisted Soxhlet extraction (MSE) is a modern extraction method that provides better extraction efficiency compared to traditional techniques, decreases extraction time and solvent consumption and increases the quality of extracts (Sulusoglu and Cavusoglu, 2013). MSE provides rapid extractions without degradation of thermolabile compounds, with significant savings in time and energy. This technique is widely used today for the extraction of bioactive substances of interest for the food and pharmaceutical industry (Proestos and Komaitis, 2008; Zhilu et al., 2006, Hong et al., 2001; Zigoneanu et al., 2008; Wu et al., 2012, Routray and Orsat 2012). In addition, another important advantage of the microwave is its applicability in a laboratory, at a pilot and at industry scale (Leonelli, and Mason, 2010). Ultrasound frequency has important effects on extraction yield. However, the effects of ultrasound on extraction yield differ depending on the nature of the plant material to be extracted. A small change in frequency can increase the yield of extract (Romdhane and Gourdon, 2002; Camel, 2000; Chan et. all, 2011; Kaufmann, 2010; Özer et all., 2018, Rodsamran and Sothornvit ,2019; Oroian et all., 2020).

\section{Material and Method}

\section{Material}

T.Indica fruit was obtained from local markets. Fresh fruit seeds sample was dried at room temperature for two weeks. The seeds are completely cleaned and separated from the fruit. The dried sample was ground into powder in a mechanical herb grinding mill before analysis.

\section{Method}

In the oil extraction of fruit samples, Soxhlet extractor modified to microwave oven was used. Oil extraction procedures were carried out with the help of $10 \mathrm{~g}$ of sample and five different solvents. These solvents; It has been designated as methyl alcohol, ethyl alcohol, chloroform, hexane and acetone. $50 \mathrm{~mL}$ of each solvent was used in the extraction process. Extraction processes resulted in approximately 10-15 minutes. After the solvent was evaporated in the evaporator, the \% yield was calculated by using the amount of oil obtained and the oil weighing obtained as a result of extraction.

Esterification process was applied to the oil samples in order to carry out the analysis. For this process, approximately $0.10-0.20 \mathrm{~g}$ of oil sample was taken and placed in a $20 \mathrm{~mL}$ test tube, $1 \mathrm{~mL}$ of $2 \mathrm{~mol} / \mathrm{L} \mathrm{KOH}$ solution was added on it. After adding $7 \mathrm{~mL}$ of $\mathrm{n}$-Heptane, the mixture in the tube was mixed vigorously for 30 seconds and then centrifuged at $2000 \mathrm{rpm}$. The clear supernatant (methyl ester) obtained was taken from the supernatant part into vials with the help of an automatic injector and made ready for injection (Carvalho et al., 2012). The vials were closed with a rubber screw cap and stored in a refrigerator at +4 degrees until analysis.

GC-MS analyzes of fatty acid methyl esters were carried out using Shimadzu GC-MS-QP2010 Ultra (Shimadzu Deutschland GmbH, GermanyA Restek Rxi-624 sil MS analytical column $(60 \mathrm{~m} \times 0.25 \mathrm{~mm} \times 1.4 \mu \mathrm{m})$, from Restek) was implemented for chromatographic separation of the analytes, using Helium as carrier gas at a constant flow rate of $2 \mathrm{~mL}$ min-1. The column temperature program was started at $40^{\circ} \mathrm{C}$ (held for $1 \mathrm{~min}$ ), raised to $240^{\circ} \mathrm{C}$ at $25^{\circ} \mathrm{C} \mathrm{min}-1$ and then to $280^{\circ} \mathrm{C}$ at $10^{\circ} \mathrm{C} \mathrm{min}-1$ (held for $5 \mathrm{~min}$ ), and completely separated the analytes in $18 \mathrm{~min}$.

Table 1. Fatty acid components of fruit seed samples (\%)

\begin{tabular}{|c|c|c|c|c|c|}
\hline Fatty Acids & Methanol & Ethanol & Chloroform & Hexane & Acetone \\
\hline Capric acid & 7.85 & N.D. & N.D. & N.D. & N.D. \\
\hline Linoleic acid & 7.31 & 4.96 & 44.44 & 18.98 & 59.23 \\
\hline cis-8 11 14-eicosatrienoic acid & 10.93 & N.D. & N.D. & N.D. & N.D. \\
\hline Arachidonic acid & 19.58 & N.D. & N.D. & N.D. & N.D. \\
\hline cis-13,16-Docosadienoicacid & 22.59 & N.D. & N.D. & N.D. & N.D. \\
\hline Lignoceric acid & 9.79 & N.D. & N.D. & N.D. & N.D. \\
\hline Nervonic acid & 14.06 & N.D. & N.D. & N.D. & N.D. \\
\hline cis-4,7,10,13,16,19-dococ acid & 7.90 & 79.52 & N.D. & N.D. & N.D. \\
\hline Palmitic acid & N.D. & 2.00 & 20.43 & 9.27 & 20.21 \\
\hline Elaidic acid & N.D. & 1.07 & 14.04 & N.D. & N.D. \\
\hline Oleic acid & N.D. & 2.97 & 6.31 & N.D. & 6.86 \\
\hline Arachidic acid & N.D. & 6.48 & 14.77 & 4.34 & 13.71 \\
\hline Gama Linelonic acid & N.D. & 1.08 & N.D. & N.D. & N.D. \\
\hline cis-11-eicosenoic acid & N.D. & 1.92 & N.D. & N.D. & \\
\hline Caproic acid & N.D. & N.D. & N.D. & 18.01 & \\
\hline Caprylic acid & N.D. & N.D. & N.D. & 3.45 & \\
\hline Undecanoic acid & N.D. & N.D. & N.D. & 45.95 & \\
\hline
\end{tabular}

N.D.: Not Detected. 


\section{Results and Discussion}

Findings obtained as a result of experimental studies are given below. In classical methods, while heating with mantle heaters, the ambient temperature is approximately $70-90^{\circ} \mathrm{C}$, while in this method, heating is carried out in a microwave oven. During this process, the power scale of the microwave oven remained at a constant 600 watts. While the analysis took at least 4 hours in the traditional Soxhlet extraction method, the total time was 10-15 minutes in the microwave extraction system. This method saves a lot of time. Depending on the volume of solvent used, a smaller volume balloon and extractor were used compared to the traditional Soxhlet extraction method. Thus, gaining from solvent with time is another advantage of the method. As a result of the analysis performed with five different solvents, crude oil was obtained in all solvents. The results are given in Table 1 .

When the fatty acids obtained with all solvents were evaluated, according to the results obtained, the most fatty acids were obtained when ethyl alcohol and methyl alcohol were used as solvents. Another best solvent has been acetone. The least number of fatty acids were obtained from hexane extract. Linoleic acid was detected in every type of solvent used. Palmitic acid and arachidic acid were detected in four solvents except methyl alcohol. Capric acid, an important fatty acid, was detected only in methyl alcohol extraction. The same is true for ligroseric acid, arachidonic acid and nervotic acid. When the results obtained in this study are compared with the literature researches; The method performed by the microwave extraction method saves a lot in terms of time and solvent consumption and is compatible with other studies. Microwave extraction method was found to be more preferable than traditional methods. Although no significant increase was observed in terms of the obtained fatty acid yields, the superiority of the MSE method emerged as an important result in terms of the same dominant fatty acids not undergoing any degradation.

As a result, it has been seen that the ultrasound assisted microwave extraction method saves time and solvent. During the analysis, five different solvents were used and the effect of the solvent on fatty acids was investigated. Fatty acids, which are among the important components for fruits and plants, can be determined by different extraction methods. The ultrasound-assisted microwave extraction method, which has been used frequently in chemical analysis methods in recent years, can be added to the Soxhlet extraction method and analyzes can be performed. It is known that the average extraction time, which is six hours in the traditional use of the Soxhlet extraction method, reduces to 30 minutes in the microwave-assisted Soxhlet extraction method, thus saving a great deal of time. Compared to the traditional extraction method, the microwave assisted extraction method has the advantage of using much less solvent, as it both reduces the solvent cost and has positive effects on the environment. It is thought that other volatile components can be made with microwaveassisted analyzes. thus, saving time and solvent.

\section{References}

Ajayi IA, Oderinde RA, Kajogbola DO, Uponi JI. 2006. Oil content and fatty acid composition of some underutilized legumes from Nigeria. Food Chemistry, 99(1): 115- 120.
Bhadoriya SS, Mishra V, Raut S, Ganeshpurkar A, Jain SK. 2012. Anti-inflammatory and antinociceptive activities of a hydroethanolic extract of Tamarindus indica leaves. Sci Pharm, 80(3): 685-700.

Camel V. 2000. Microwave-assisted solvent extraction of environmental samples. Trends in Analytical Chemistry, 19(4): 229-248.

Carvalho, MS, Mendonça MA, Pinho DM, Resck IS, Suarez P. A. 2012. Chromatographic analyses of fatty acid methyl esters by HPLC-UV and GC-FID. Journal of the Brazilian Chemical Society, 23(4): 763-769.

Chan CH, Yusoff R, Ngoh GC, Kung FWL. 2011. Microwaveassisted extractions of active ingredients from plants. Journal of Chromatography A, 1218(37): 6213-6225.

De Caluwé E, Halamouá K, Van Damme P. 2010. Tamarindus indica L. - A review of traditional uses, phytochemistry and pharmacology. Afrika focus, 23(1): 53-83.

Donnis B, Egeberg RG, Blom P, Knudsen KG. 2009. Hydroprocessing of bio-oils and oxygenates to hydrocarbons. Understanding the reaction routes. Topics in Catalysis, 52(3): 229-240.

Karaca E, Aytaç S. 2007. Yağ bitkilerinde yă asitleri kompozisyonu üzerine etki eden faktörler, O.M.Ü. Zir. Fak. Dergisi, 22(1): 123-131.

Kaufmann B, Christen P. 2010. Recent extraction techniques for natural products: microwave-assisted extraction and pressurised solvent extraction. Phytochem. Anal, 13: 105113.

Leonelli C, Mason TJ. 2010. Microwave and ultrasonic processing: now a realistic option for industry. Chemical Engineering and Processing: Process Intensification, 49(9): 885-900.

Oroian M, Dranca F, Ursachi F. 2020. Comparative evaluation of maceration, microwave and ultrasonic-assisted extraction of phenolic compounds from propolis. Journal of food science and technology, 57(1): 70-78.

Özer P, Görgüç A, Y1lmaz FM. 2018. Mikrodalga teknolojisinin bitkisel dokulardan makro ve mikro bileşenlerin özütlenmesinde kullanımı. Gıda Dergisi, 43(5): 765-775.

Proestos C, Komaitis M. 2008. Application of microwaveassisted extraction to the fast extraction of plant phenolic compounds. LWT-food science and technology, 41(4): 652659.

Rodsamran P, Sothornvit R. 2019. Extraction of phenolic compounds from lime peel waste using ultrasonic-assisted and microwave-assisted extractions. Food bioscience, 28: 6673.

Romdhane M, Gourdon C. 2002. Investigation in solid-liquid extraction: influence of ultrasound. Chemical Engineering Journal, 87(1): 11-19.

Routray W, Orsat V. 2012. Microwave-assisted extraction of flavonoids: a review. Food and Bioprocess Technology, 5(2): 409-424.

Sulusoglu M, Cavusoglu A. 2013. Micropropagation of cherry laurel (Prunus laurocerasus L). J Food Agr Environ, 11: 576579.

Taşan M, Dağlığlu O. 2005. "Trans yağ asitlerinin yapıs1, oluşumu ve gidalarla alınması", Tekirdağ Ziraat Fakültesi Dergisi 2(1): 79-88.

Wu T, Yan J, Liu R, Marcone MF, Aisa HA, Tsao R. 2012. Optimization of microwave-assisted extraction of phenolics from potato and its downstream waste using orthogonal array design. Food Chemistry, 133(4): 1292-1298.

Zhilu A, Juan G, Yuhong W, Yanxia L, Qiuyan Z. 2006. Microwave-assisted extraction technique of apple polyphenols in apple pomace [J]. Transactions of the Chinese Society of Agricultural Engineering, 6 . 